\title{
Concurrent use of indacaterol plus tiotropium in patients with COPD provides superior bronchodilation compared with tiotropium alone: a randomised, double-blind comparison
}

\author{
Donald A Mahler, ${ }^{1,2}$ Anthony D'Urzo, ${ }^{3}$ Eric D Bateman, ${ }^{4}$ Serir A Özkan, ${ }^{5}$ Tracy White, ${ }^{6}$ \\ Clare Peckitt, ${ }^{7}$ Cheryl Lassen, ${ }^{7}$ Benjamin Kramer, ${ }^{6}$ on behalf of the INTRUST-1 and \\ INTRUST-2 study investigators
}

\begin{abstract}
${ }^{1}$ Section of Pulmonary and Critical Care Medicine, Dartmouth Medical School, Hanover, New Hampshire, USA ${ }^{2}$ Dartmouth-Hitchcock Medical Center, Lebanon, New Hampshire, USA ${ }^{3}$ Department of Family and Community Medicine (DFCM), University of Toronto, Toronto, Canada

${ }^{4}$ Division of Pulmonology, Department of Medicine, University of Cape Town, Cape Town, South Africa

${ }^{5}$ Division of Pulmonary Medicine, Izmir Training Hospital for Pulmonary Medicine and Surgery, Izmir, Turkey

${ }^{6}$ Novartis Pharmaceuticals, East Hanover, New Jersey, USA

${ }^{7}$ Novartis Horsham Research Centre, Horsham, West Sussex, UK
\end{abstract}

\section{Correspondence to}

Dr Donald A Mahler, Section of Pulmonary and Critical Care

Medicine, $5 \mathrm{C}$

Dartmouth-Hitchcock Medical Center, One Medical Center Drive, Lebanon, $\mathrm{NH}$ 03756-0001, USA: donald.a.mahler@hitchcock.org

Received 21 September 2011 Accepted 29 March 2012 Published Online First 27 April 2012

\section{ABSTRACT}

Background Current guidelines recommend treatment with one or more long-acting bronchodilators for patients with moderate or more severe chronic obstructive pulmonary disease (COPD). The authors investigated the approach of dual bronchodilation using indacaterol, a once-daily long-acting $\beta_{2}$ agonist, and the long-acting muscarinic antagonist tiotropium, compared with tiotropium alone.

Methods In two identically designed, double-blind, 12-week studies, patients with moderate to severe COPD were randomised to indacaterol $150 \mu \mathrm{g}$ once daily or matching placebo. All patients concurrently received open-label tiotropium $18 \mu \mathrm{g}$ once daily. The primary outcome was standardised area under the curve of forced expiratory volume in $1 \mathrm{~s}\left(\mathrm{FEV}_{1}\right)$ from $5 \mathrm{~min}$ to $8 \mathrm{~h}$ post dose at week 12 . The key secondary outcome was $24 \mathrm{~h}$ post-dose ('trough') FEV ${ }_{1}$ at week 12. Resting inspiratory capacity (IC) was measured in a subgroup. Results 1134 and 1142 patients were randomised in studies 1 and 2; 94\% and 94\% completed. Compared with monotherapy, concurrent therapy increased $\mathrm{FEV}_{1}$ (area under the curve by 130 and $120 \mathrm{ml}$, trough by 80 and $70 \mathrm{ml}$; all $\mathrm{p}<0.001$ ) and trough IC (by 130 and $100 \mathrm{ml}, \mathrm{p}<0.01)$. Cough was more common with indacaterol plus tiotropium (10\% and $9 \%)$ than with tiotropium alone (4\% and $4 \%)$. Most cases ( 90\%) of cough were mild. Other adverse events were similar for the treatment groups.

Conclusions Compared with tiotropium monotherapy, indacaterol plus tiotropium provided greater bronchodilation and lung deflation (reflected by increased resting IC). Adverse events were similar between treatments apart from mild cough being more common with indacaterol plus tiotropium. These results support COPD guideline recommendations to combine bronchodilators with different mechanisms of action.

Trial registration numbers NCT00846586 and NCT00877383.

\section{INTRODUCTION}

Current guidelines recommend treatment with one or more long-acting bronchodilators for patients with moderate or more severe chronic obstructive pulmonary disease (COPD) ${ }^{1-3}$ The candidate

\section{Key messages}

What is the key question?

- Can additional efficacy be obtained by treating patients with chronic obstructive pulmonary disease (COPD) with concurrent once-daily inhaled bronchodilators compared with a single bronchodilator alone, without incurring increased adverse events?

What is the bottom line?

- The results of two studies show significant additional bronchodilation (forced expiratory volume in $1 \mathrm{~s}$ ) and lung deflation (increased inspiratory capacity) after 12 weeks of treatment with concurrent indacaterol and tiotropium beyond that achieved with tiotropium alone. Safety profiles were similar apart from an increase in mild cough with concurrent treatment compared with tiotropium alone.

Why read on?

- These are the first 12-week studies to report on the combined efficacy and safety of two oncedaily bronchodilators, indacaterol and tiotropium. The results demonstrate that bronchodilators with different mechanisms of action can provide increased benefit with little or no increase in risk of clinically relevant adverse events.

agents include the long-acting muscarinic antagonist (LAMA) tiotropium, given once daily, ${ }^{4}$ and the long-acting $\beta_{2}$ agonists (LABAs) formoterol and salmeterol, given twice daily, or the once-daily indacaterol. Given as bronchodilator monotherapy, indacaterol has been shown to be effective and to have a good safety profile in patients with moderate to severe COPD in placebo-controlled studies of up to 1 year in duration. ${ }^{6-9}$ Indacaterol has demonstrated superiority in bronchodilator efficacy and clinical outcomes compared with the twice daily LABAs, ${ }^{6-8}$ and was shown to perform at least as well as tiotropium. ${ }^{9-11}$

In general, the addition of a second bronchodilator from a different pharmacological class has 
been shown to improve lung function, symptoms and health status compared with a single bronchodilator. ${ }^{12-18}$ However, much of the data supporting combination bronchodilator treatment involves short-term studies ${ }^{14-16}$ or the use of shortacting bronchodilators. ${ }^{12} 13$ There are limited data for the combination of once-daily bronchodilators. ${ }^{19}$ Van Noord and colleagues $^{19}$ reported that a once-daily dual bronchodilator consisting of indacaterol and glycopyrronium provided greater bronchodilation compared with indacaterol monotherapy and placebo for 7 days in 135 patients with moderate to severe COPD.

In the present study, we report the results of two identically designed studies examining the efficacy of two once-daily inhaled bronchodilator medications, indacaterol and tiotropium. The hypothesis of the two studies was that the concurrent use of a once-daily LABA and a once-daily LAMA would provide greater bronchodilation and reduce hyperinflation compared with a LAMA alone. Duplicate studies were conducted to meet US regulatory requirements.

\section{METHODS \\ Patients}

Participating physicians enrolled patients aged $\geq 40$ years with moderate to severe COPD (defined according to Global Initiative for Chronic Obstructive Lung Disease (GOLD) 2007 criteria $^{20}$ ), with a smoking history $\geq 10$ pack-years and postbronchodilator (salbutamol $100 \mu \mathrm{g} \times$ four puffs) forced expiratory volume in $1 \mathrm{~s}\left(\mathrm{FEV}_{1}\right) \leq 65 \%$ and $\geq 30 \%$ of predicted normal, and post-bronchodilator $\mathrm{FEV}_{1}$ /forced vital capacity $<70 \%$ at screening. The midpoint of GOLD stage II, namely $\mathrm{FEV}_{1} 65 \%$ of predicted, was chosen as the upper limit for the protocol of this study evaluating two long-acting bronchodilators to target a more 'severe' GOLD II patient population that would benefit from combined bronchodilator treatment. GOLD guidelines at that time stated that one or more long-acting bronchodilators should be used for patients in GOLD stage II, and we believe that in practice this would comprise initial treatment with a single bronchodilator with another longacting bronchodilator being added as patients become more symptomatic. Patients were not eligible if they had a history of asthma or had experienced a respiratory tract infection or COPD exacerbation within the previous 6 weeks.

\section{Study design}

Two identically designed, randomised, double-blind, 12-week studies were conducted. Study 1 involved 186 centres in 14 countries: Argentina (10), Australia (6), Colombia (5), Denmark (5), Germany (25), Greece (4), Guatemala (5), Mexico (5), Peru (6), Philippines (2), South Africa (6), Spain (13), Turkey (13) and USA (81). Study 2 had 182 centres in 11 countries: Argentina (9), Canada (16), Colombia (3), Czech Republic (9), Hungary (4), India (9), Netherlands (6), Philippines (3), Slovakia (10), Spain (11) and USA (102). Data were collected from outpatient clinics and physicians' offices.

\section{Study treatments}

Patients were randomised to treatment with indacaterol $150 \mu \mathrm{g}$ once daily or placebo to indacaterol. All patients concurrently received tiotropium $18 \mu \mathrm{g}$ once daily, and all treatments were taken once daily via their proprietary single-dose dry-powder inhalers. Study treatments were taken at the same time each morning and in the fixed order of tiotropium followed by indacaterol/placebo, to be taken as soon after each other as possible. Salbutamol (albuterol in the USA) was available for as-needed use.

Patients receiving inhaled corticosteroids (ICS) at baseline continued treatment (or were switched to ICS monotherapy if taken as a fixed combination with a bronchodilator) at equivalent dose and regimen during the study. Other COPD treatments were withdrawn with appropriate washouts prior to screening (short-acting $\beta_{2}$ agonists other than allowed in the study, $6 \mathrm{~h}$; short-acting anticholinergics, $8 \mathrm{~h}$; LABAs, $48 \mathrm{~h}$; theophylline, 7 days).

\section{Randomisation and blinding}

Randomisation (1:1) was performed using an automated interactive voice response system and was stratified by COPD severity (moderate or severe), with balance maintained at country level. Patients and staff at participating centres were unaware of treatment assignment. The tiotropium in both arms was given open label, and blinding was achieved by the use of placebo to indacaterol (ie, placebo given via the inhaler used for indacaterol). Patients, investigators, those performing the assessments and data analysts were blinded unless an emergency arose for a patient.

\section{Objectives, assessments and outcome measures}

The primary objective was to demonstrate superiority of indacaterol plus tiotropium versus tiotropium plus placebo in its effect on standardised area under the curve (AUC) of $\mathrm{FEV}_{1}$ from 5 min to $8 \mathrm{~h}$ post dose $\left(\mathrm{FEV}_{1} \mathrm{AUC}_{5 \mathrm{~min}-8 \mathrm{~h}}\right)$ after 12 weeks (primary variable). The key secondary variable was $24 \mathrm{~h}$ post-dose $\mathrm{FEV}_{1}$ ('trough'; mean of measurements made at $23 \mathrm{~h} 10 \mathrm{~min}$ and $23 \mathrm{~h}$ 45 min post dose) at week 12 . Further efficacy variables included other spirometric values $\left(\mathrm{FEV}_{1}\right.$ at other times and forced vital capacity). Exploratory variables were inspiratory capacity (IC, measured in a subgroup of approximately 120 patients per treatment arm) and use of as-needed salbutamol and symptoms. The patients in whom IC was measured were from study centres that elected to perform this measurement. Patients used diaries to record the number of salbutamol puffs used and severity of cough, wheeze, breathlessness and sputum production and colour during the last $12 \mathrm{~h}$ on four-point scales of increasing severity, each morning (premedication) and evening; there is no established threshold of clinical significance for these measures.

Safety data included adverse events, notable vital signs (pulse, blood pressure), blood chemistry (blood glucose, serum potassium) and ECG (QTc interval, corrected using Fridericia's formula) at any time post baseline (measured pre dose and 30 min post dose at weeks 4, 8 and 12).

\section{Statistical methods}

Two populations were defined for analysis. The full analysis (intention-to-treat) population comprised randomised patients who received at least one dose of the study drug, analysed according to allocated treatment group. The safety population comprised patients who received at least one dose of the study drug, analysed according to treatment received.

The primary variable ( $\mathrm{FEV}_{1} \mathrm{AUC}_{5 \mathrm{~min}-8 \mathrm{~h}}$ after 12 weeks) was analysed using a mixed-model analysis of covariance containing treatment as a fixed effect and, as covariates, baseline $\mathrm{FEV}_{1}$ and $\mathrm{FEV}_{1}$ before and after salbutamol and before and after ipratropium inhalation. The model also included disease severity (moderate/severe), country, smoking history and ICS use as fixed effects and centre nested within country as a random effect. Similar methods were used to analyse secondary efficacy variables, with appropriate baseline measurements as covariates. 
To allow for multiplicity, a hierarchical testing procedure was used to maintain an $\alpha$ level of 0.05 for the primary and key secondary variables $\left(\mathrm{FEV}_{1} \mathrm{AUC}_{5 \mathrm{~min}-8 \mathrm{~h}}\right.$ and trough $\mathrm{FEV}_{1}$ after 12 weeks). Any missing values were carried forward from the latest available of the values at weeks 4 or 8 ('last observation carried forward'). Exploratory analyses of $\mathrm{FEV}_{1} \mathrm{AUC}_{5 \mathrm{~min}-8 \mathrm{~h}}$ at week 12 were performed in patient subgroups according to disease severity (moderate or less, severe or worse), smoking history (current smoker, ex-smoker) and the use of ICS at baseline (yes, no), using appropriate interaction terms and covariates.

Results are shown as least squares means with SEs for group mean values and 95\% CIs for differences between treatments. Adverse events and other safety data are summarised descriptively.

For the primary analysis, to show superiority in standardised $\mathrm{FEV}_{1} \mathrm{AUC}_{5 \mathrm{~min}-8 \mathrm{~h}}$ by $60 \mathrm{ml}^{17}$ with a SD of $220 \mathrm{ml}, 478$ evaluable patients per arm were needed for $98 \%$ power which, with an assumed dropout of $15 \%$, required 563 patients per arm or a total of 1126. For the key secondary analysis of trough $\mathrm{FEV}_{1}$, assuming a difference of $45 \mathrm{ml}^{5} 14$ and a SD of $225 \mathrm{ml}, 478$ evaluable patients per arm would provide $87 \%$ power. Since the key secondary variable would only be tested if the primary objective was significant, the power for the key secondary would be $85 \%$ (ie, $87 \% \times 98 \%$ ).

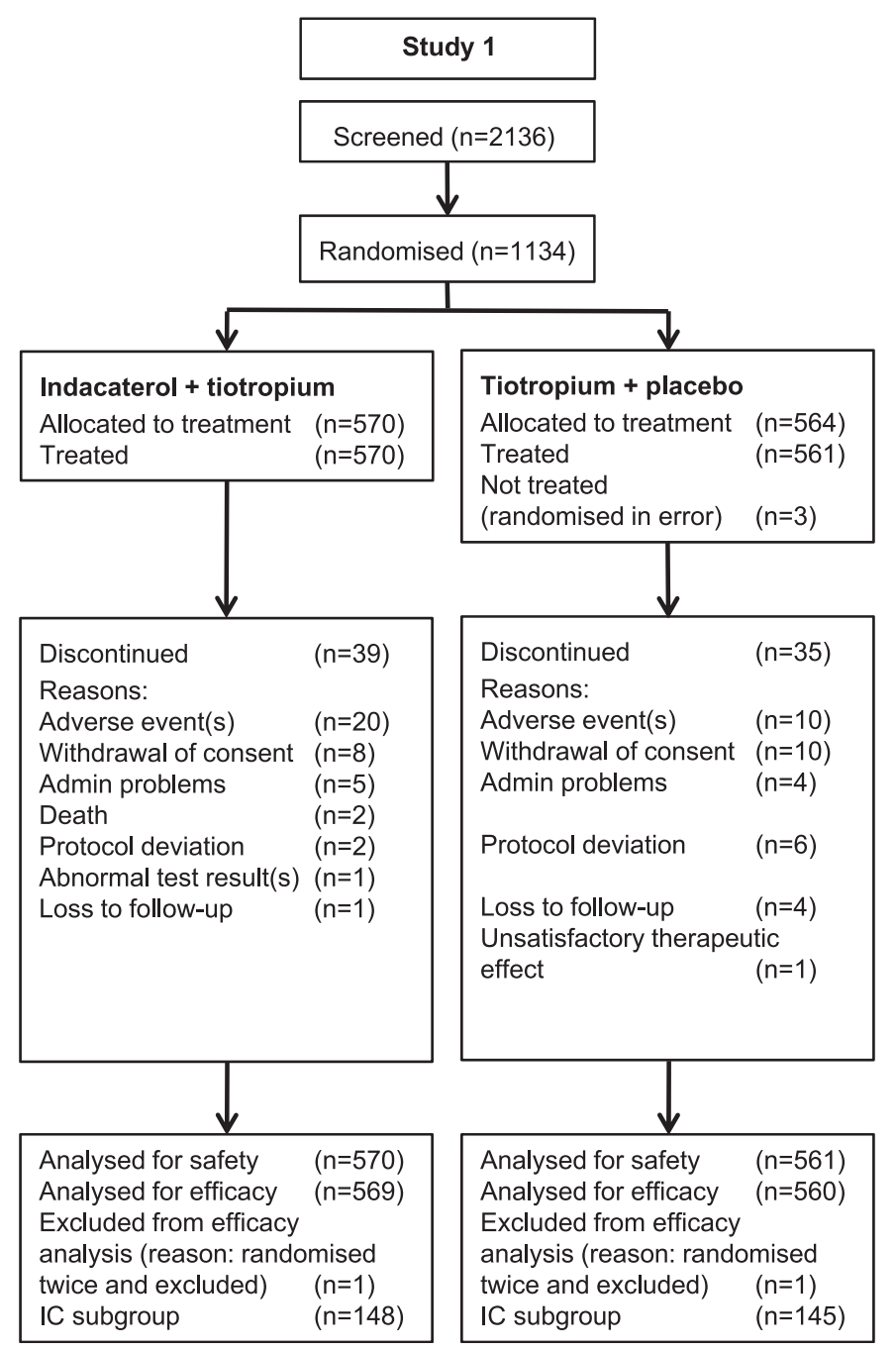

\section{RESULTS}

The studies were conducted between March 2009 and March 2010.

\section{Patients}

Patient disposition is shown in figure 1. The main reason for screening failure was not meeting diagnostic/severity criteria, followed by unacceptable test procedure results and withdrawal of consent. Completion rates were similar between treatment groups and studies: $93 \%$ and $94 \%$ of patients in study 1, and $95 \%$ and $94 \%$ in study 2 . Patient demographics and other baseline characteristics were similar between the two treatment groups, apart from a slightly higher proportion of baseline ICS users in the indacaterol plus tiotropium treatment group of study 2. The two studies were well balanced, apart from a higher proportion of Asian patients in study 2 (table 1).

\section{Lung function}

In both studies the primary objective was met, and superiority of indacaterol plus tiotropium versus tiotropium plus placebo was demonstrated for $\mathrm{FEV}_{1} \mathrm{AUC}_{5 \mathrm{~min}-8 \mathrm{~h}}$ at week 12, with differences of $130 \mathrm{ml}(95 \%$ CI 100 to 150$)$ and $120 \mathrm{ml}(95 \%$ CI 90 to 140$)$ in studies 1 and 2, respectively (both $\mathrm{p}<0.001$ ). Results for $\mathrm{FEV}_{1}$ AUC $_{5 \mathrm{~min}-8 \mathrm{~h}}$ in the subgroups analysed according to COPD severity, smoking status and ICS use are shown in table 2.

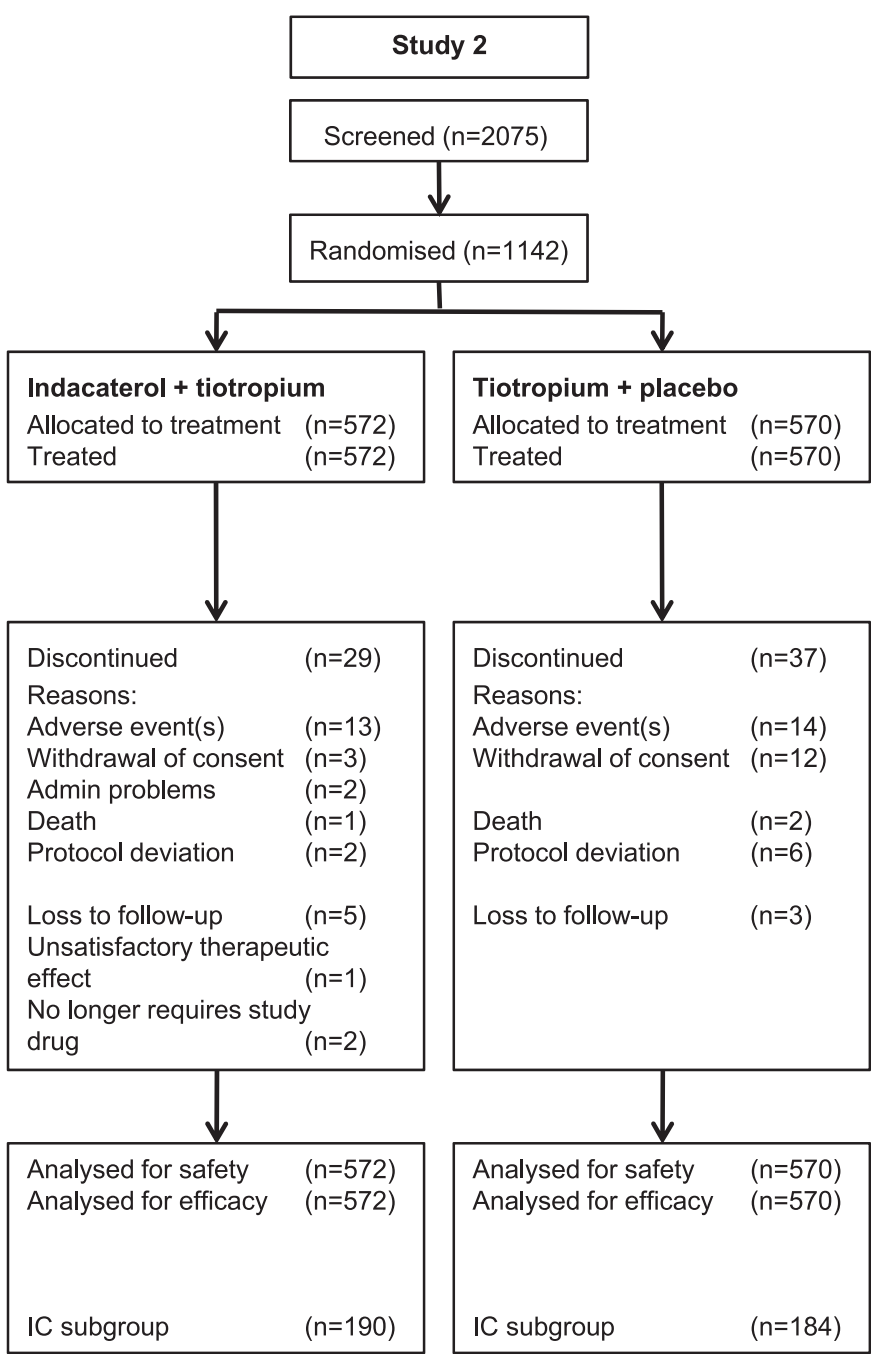

Figure 1 Patient flow through studies. IC, inspiratory capacity. 
Table 1 Demographics and baseline characteristics

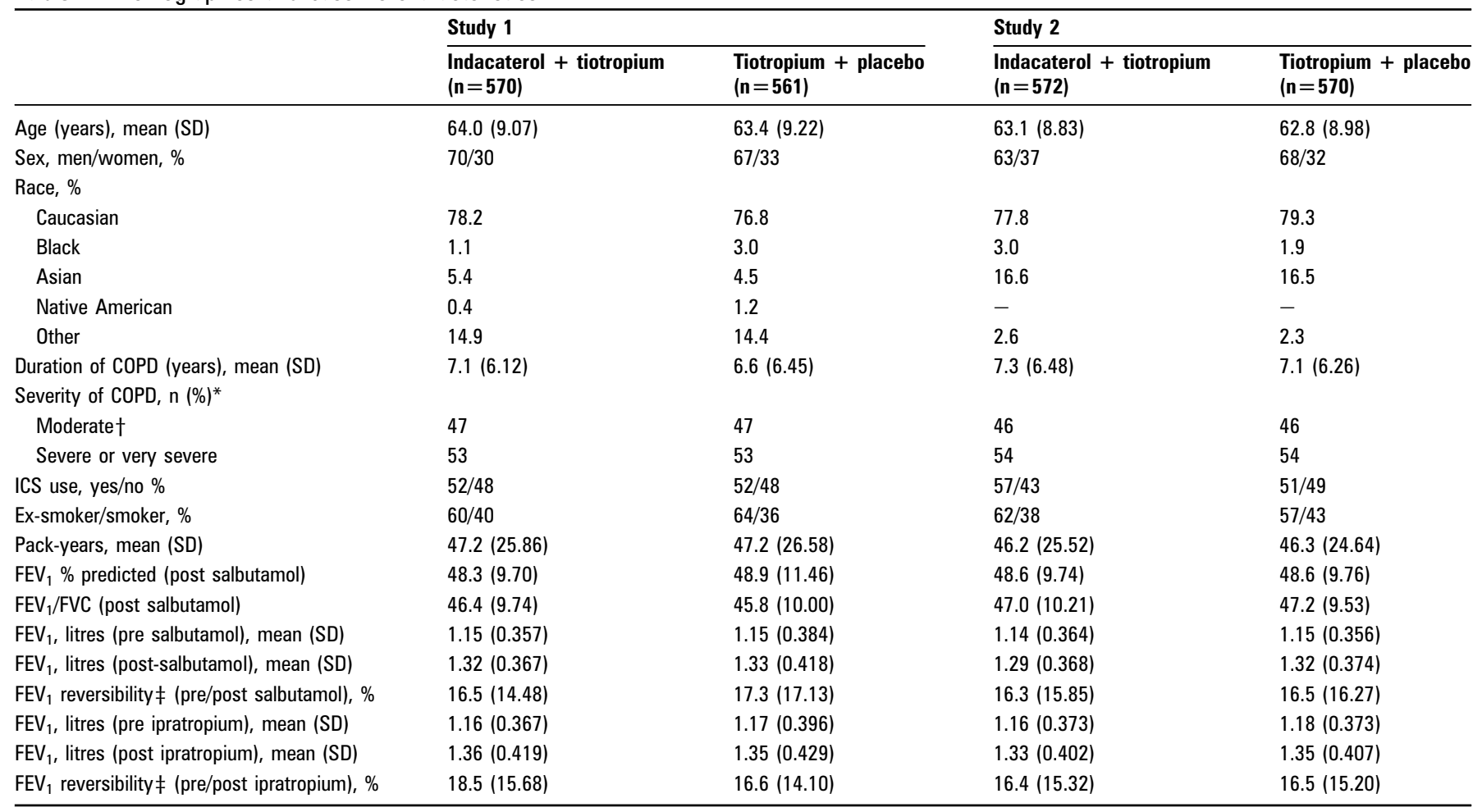

*Global Initiative for Chronic Obstructive Lung Disease (GOLD) 2007. Data missing for one patient in study 2.

tIncludes one patient (study 1, tiotropium group) with mild severity.

$\ddagger$ At screening, spirometry measurements were taken to assess bronchodilator reversibility, first to a short-acting $\beta_{2}$ agonist (FEV $\mathrm{F}_{1}$ measured $10-15$ min after inhalation of $4 \times 100 \mu \mathrm{g}$ puffs of salbutamol (equivalent to $4 \times 90 \mu \mathrm{g}$ albuterol ex-mouthpiece) compared with pre-bronchodilator value) and, on the next morning, to an anticholinergic (FEV ${ }_{1}$ increase $1 \mathrm{~h}$ after inhalation of $2 \times$ $21 \mu \mathrm{g}$ ipratropium bromide (equivalent to $2 \times 17 \mu \mathrm{g}$ ipratropium ex-mouthpiece) compared with pre-bronchodilator value).

$\mathrm{COPD}$, chronic obstructive pulmonary disease; $\mathrm{FEV}_{1}$, forced expiratory volume in $1 \mathrm{~s}$; FVC, forced vital capacity; ICS, inhaled corticosteroid.

Differences between indacaterol plus tiotropium and tiotropium plus placebo remained statistically significant in all subgroups, although the differences within each pair of subgroups were wider in study 2 than in study 1, particularly for smokers versus ex-smokers.

Indacaterol plus tiotropium also performed better than tiotropium plus placebo for the key secondary variable, trough $\mathrm{FEV}_{1}$ (last observation carried forward) at week 12, with differences of $80 \mathrm{ml}(95 \%$ CI 50 to 100$)$ and $70 \mathrm{ml}$ (95\% CI 50 to
90) (both $\mathrm{p}<0.001$ ). Again, statistically significant differences between the two treatments were maintained in subgroups analysed according to COPD severity, smoking status and ICS use (table 2).

After the first dose on day 1 of treatment, indacaterol plus tiotropium had a significantly greater effect than tiotropium plus placebo on $\mathrm{FEV}_{1}$ at $5 \mathrm{~min}$ post dose, with differences of $90 \mathrm{ml}(95 \%$ CI 80 to $100 \mathrm{ml})$ and $80 \mathrm{ml}(95 \%$ CI 70 to $90 \mathrm{ml})$ (both $\mathrm{p}<0.001)$. At this time point, least square mean increases

Table 2 Differences between treatments (indacaterol plus tiotropium-tiotropium plus placebo) in $\mathrm{FEV}_{1} \mathrm{AUC}_{5 \mathrm{~min}-8 \mathrm{~h}}$ and trough $\mathrm{FEV}_{1}$ in patient subgroups analysed according to COPD severity, smoking status and ICS use*

\begin{tabular}{|c|c|c|c|c|}
\hline & \multicolumn{4}{|c|}{ Differences between indacaterol + tiotropium versus tiotropium + placebo } \\
\hline & \multicolumn{2}{|l|}{ FEV $_{1}$ AUC $_{5 \min -8 \mathrm{~h}}$} & \multicolumn{2}{|l|}{ Trough FEV $_{1}$} \\
\hline & Study 1 & Study 2 & Study 1 & Study 2 \\
\hline Moderate $\neq$ & $120 \mathrm{ml}(90$ to 160$)(\mathrm{n}=233 / 237) \S$ & $130 \mathrm{ml}(90$ to 160$)(n=247 / 237)$ & $90 \mathrm{ml}(50$ to 130$)(\mathrm{n}=259 / 260)$ & $90 \mathrm{ml}(60$ to 120$)(\mathrm{n}=261 / 258)$ \\
\hline Severe or very severe & $130 \mathrm{ml}(100$ to 160$)(\mathrm{n}=272 / 267)$ & $110 \mathrm{ml}(80$ to 140$)(n=283 / 267)$ & $70 \mathrm{ml}(30$ to 110$)(\mathrm{n}=302 / 289)$ & $60 \mathrm{ml}(30$ to 90$)(\mathrm{n}=304 / 306)$ \\
\hline \multicolumn{5}{|l|}{ Smoking status } \\
\hline \multicolumn{5}{|l|}{ ICS use } \\
\hline ICS non-users & $120 \mathrm{ml}(90$ to 160$)(n=242 / 236)$ & $140 \mathrm{ml}(100$ to 170$)(n=229 / 251)$ & $70 \mathrm{ml}(30$ to 110$)(\mathrm{n}=271 / 260)$ & $90 \mathrm{ml}(60$ to 120$)(\mathrm{n}=244 / 274)$ \\
\hline ICS users & $130 \mathrm{ml}(100$ to 160$)(\mathrm{n}=263 / 268)$ & $100 \mathrm{ml}(70$ to 140$)(\mathrm{n}=301 / 253)$ & $80 \mathrm{ml}(50$ to 120$)(\mathrm{n}=290 / 289)$ & $60 \mathrm{ml}(30$ to 90$)(\mathrm{n}=321 / 290)$ \\
\hline
\end{tabular}




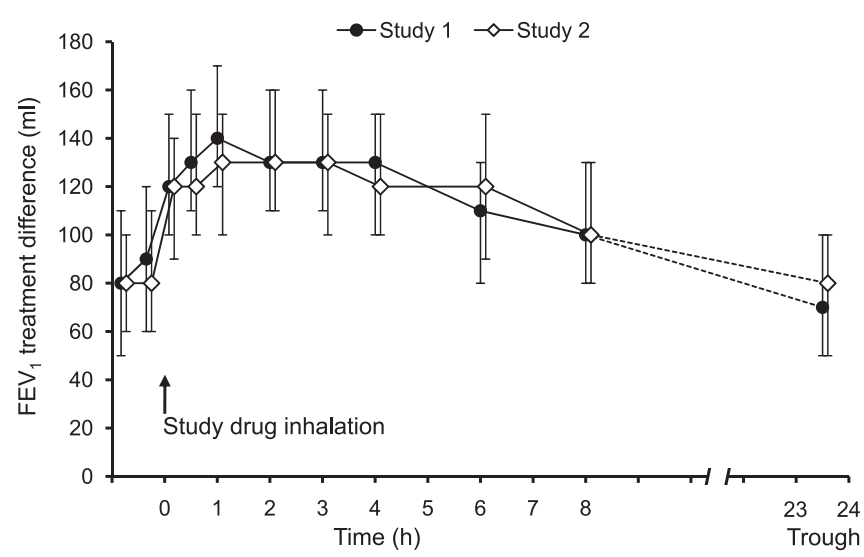

Figure 2 Differences between treatments (indacaterol plus tiotropium-tiotropium plus placebo) in effect on forced expiratory volume in 1 $\mathrm{s}\left(\mathrm{FEV}_{1}\right)$ at intervals post dose at week 12. Data are least squares means and $95 \%$ Cls. All differences significant at $p<0.001$. (Treatment contrasts for the trough measurements shown in the figure are without imputation for missing values.)

from baseline in $\mathrm{FEV}_{1}$ were $130 \mathrm{ml}$ (95\% CI 120 to 150) and $120 \mathrm{ml}$ (95\% CI 110 to 140) with indacaterol plus tiotropium treatment and $40 \mathrm{ml}(95 \% \mathrm{CI} 30$ to 60$)$ and $50 \mathrm{ml}(95 \%$ CI 40 to 60 ) with tiotropium plus placebo. Indacaterol plus tiotropium was superior to tiotropium plus placebo for $\mathrm{FEV}_{1} \mathrm{AUC}_{5 \min -8 \mathrm{~h}}$ on day 1 (differences of 80 (95\% CI 60 to 90$)$ and $70 \mathrm{ml}(95 \%$ CI 50 to 80$), \mathrm{p}<0.001)$ and for trough $\mathrm{FEV}_{1}$ measured on day 2 (differences of 90 (95\% CI 70 to 110$)$ and $80 \mathrm{ml}(95 \%$ CI 60 to 90), $\mathrm{p}<0.001)$.

Measurements of $\mathrm{FEV}_{1}$ at individual time points after dosing at week 12 are shown in figure 2 , with significant betweentreatment differences at each time point $(p<0.001)$. (Treatment contrasts for the trough measurements shown in the figure are without imputation for missing values.)

IC treatment contrasts at week 12 are shown in figure 3 . The differences between indacaterol plus tiotropium and tiotropium plus placebo treatment were statistically significant at each time point, including trough ( $24 \mathrm{~h}$ post dose).

\section{Patient-reported symptoms and use of as-needed salbutamol}

Over the 12 weeks of the study, the decreases from baseline in COPD symptom scores and the use of as-needed salbutamol

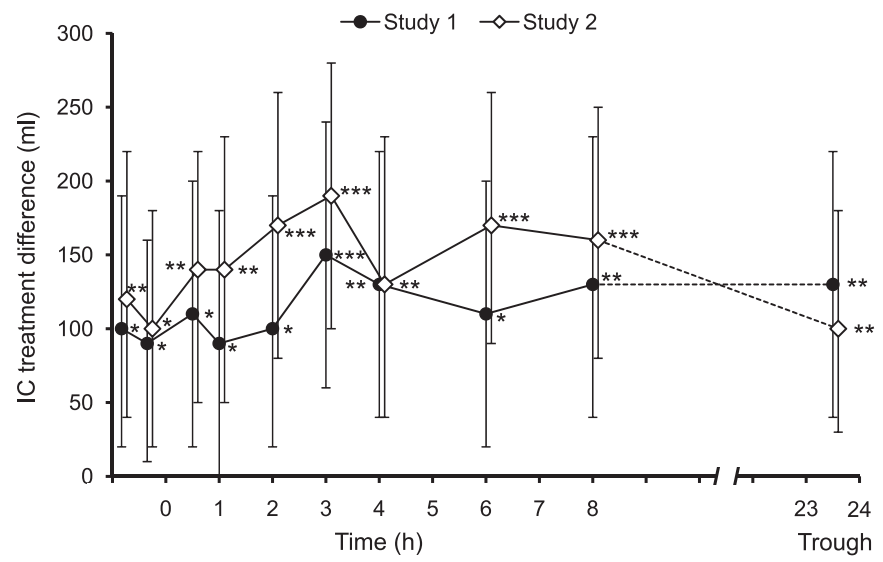

Figure 3 Differences between treatments (indacaterol plus tiotropium-tiotropium plus placebo) in effect on inspiratory capacity (IC) at intervals post dose at week 12. Data are least squares means and $95 \%$ Cls. All differences significant at ${ }^{*} \mathrm{p}<0.05,{ }^{* *} \mathrm{p}<0.01,{ }^{* * *} \mathrm{p}<0.001$. were statistically significantly greater in the combined treatment group in both studies (table 3).

\section{Safety}

Adverse events were reported for similar proportions of patients in the two treatment groups in both studies (table 4). Many of the most common events reflected the disease characteristics of COPD and had a similar incidence in all four treatment groups. The most common adverse event overall was COPD worsening. Cough was more common with the indacaterol plus tiotropium treatment. Most cases of cough with concurrent treatment were mild (54/59, 92\%; and 46/52, 89\%), and only one (moderate) case led to study drug discontinuation. Other differences between treatment groups (eg, in muscle spasms and dyspnoea) were small and not observed consistently in the two studies.

Two patients died during the treatment period in study 1 , both in the indacaterol plus tiotropium treatment group (causes were anaphylaxis and myocardial infarction). Three patients died during the treatment period in study 2 , one in the indacaterol plus tiotropium group (cause was myocardial infarction) and two in the tiotropium group (causes were unknown and cardiac arrest). Another two patients died in the 30 days following discontinuation of tiotropium (acute renal failure) or indacaterol plus tiotropium treatment (unknown cause). In the opinion of the investigators, apart from the death due to cardiac arrest (in the tiotropium group of study 2), all were considered unrelated to study treatment.

Serious adverse events were reported for similar proportions of patients in the indacaterol plus tiotropium and monotherapy groups: $3.7 \%$ and $3.0 \%$ (study 1 ) and $3.3 \%$ and $3.2 \%$ (study 2 ). The primary system organ classes in which $1 \%$ or more of patients had a serious adverse event were 'respiratory, thoracic and mediastinal disorders' (1.1\% and $1.6 \%$ with indacaterol plus tiotropium treatment; $2.1 \%$ and $1.6 \%$ with tiotropium), mostly comprising COPD worsening $(1.1 \%$ and $1.6 \%$ with indacaterol plus tiotropium; $2.0 \%$ and $1.6 \%$ with tiotropium); and 'infections and infestations' $(1.1 \%$ and $1.2 \%$ with indacaterol plus tiotropium treatment; $0.5 \%$ and $0.7 \%$ with tiotropium), which included pneumonia and lower respiratory tract infections.

Results for vital signs, plasma potassium, blood glucose and OTc intervals are shown in table 5. Findings were generally similar between the two treatments; a numerically higher incidence of elevated systolic blood pressure with indacaterol plus tiotropium treatment in study 1 was not observed in study 2 .

\section{DISCUSSION}

Several placebo-controlled studies have demonstrated the efficacy and safety of indacaterol given as long-acting bronchodilator monotherapy in patients with moderate to severe COPD. ${ }^{67921}$ Its bronchodilator effect was shown to be superior to the twice-daily $\mathrm{LABAs}^{6-8}$ and at least as effective as tiotropium, although indacaterol had the faster onset of effect on first dose. ${ }^{9-11}$ Indacaterol was also shown to improve clinical outcomes (dyspnoea and health status) to a statistically significantly greater extent than tiotropium. ${ }^{10}$

Coadministration of indacaterol and tiotropium provided significantly greater bronchodilation (AUC and trough $\mathrm{FEV}_{1}$ ) compared with tiotropium alone. These differences were seen from the first dose onwards. The statistically significant differential bronchodilator effect was maintained in patient subgroups irrespective of baseline COPD severity, smoking status or ICS use. The differential between the two treatments was fairly constant between the subgroups in study 1 but 
Table 3 Patient-reported symptoms and use of as-needed salbutamol over 12 weeks

\begin{tabular}{|c|c|c|c|c|}
\hline & \multicolumn{2}{|l|}{ Study 1} & \multicolumn{2}{|l|}{ Study 2} \\
\hline & Indacaterol + tiotropium & Tiotropium + placebo & Indacaterol + tiotropium & Tiotropium + placebo \\
\hline \multicolumn{5}{|l|}{ Baseline* symptom score $\dagger$} \\
\hline Daytime & $6.2(2.97)$ & $5.7(2.90)$ & $6.1(2.94)$ & $6.1(2.71)$ \\
\hline Night-time & $5.6(3.16)$ & $5.2(3.03)$ & $5.5(3.06)$ & $5.5(2.86)$ \\
\hline $\begin{array}{l}\text { Change from baseline symptom score } \\
\text { (full } 24 \mathrm{~h} \text { ) during treatment }\end{array}$ & $-2.1(0.20)$ & $-1.6(0.21)$ & $-2.2(0.21)$ & $-1.5(0.21)$ \\
\hline $\begin{array}{l}\text { Change from baseline symptom score } \\
\text { (daytime) during treatment }\end{array}$ & $-1.2(0.10)$ & $-0.9(0.10)$ & $-1.1(0.12)$ & $-0.8(0.12)$ \\
\hline Difference between treatments & $-0.3(-0.5$ to -0.06$)$ & & $-0.4(-0.6$ to -0.1$)$ & \\
\hline $\begin{array}{l}\text { Change from baseline symptom score } \\
\text { (night-time) during treatment }\end{array}$ & $-1.0(0.10)$ & $-0.8(0.10)$ & $-1.0(0.12)$ & $-0.7(0.12)$ \\
\hline Difference between treatments & $-0.2(-0.4$ to -0.03$)$ & & $-0.3(-0.5$ to -0.1$)$ & \\
\hline Baseline $†$ salbutamol use (puffs/day) & $5.5(4.24)(n=538)$ & $5.0(4.45)(n=538)$ & $4.9(3.91)(n=555)$ & $4.5(3.97)(n=543)$ \\
\hline Days during treatment with no salbutamol use (\%) & $43.2(1.91)$ & $34.2(1.93)$ & $38.7(1.94)$ & $33.6(1.92)$ \\
\hline Difference between treatments & 9.0 (5.1 to 12.8 ) & & $5.1(1.4$ to 8.8$)$ & \\
\hline
\end{tabular}

Baseline values are raw means (SD). Changes from baseline are least square means (SE) and treatment comparisons are least square means (95\% $\mathrm{Cl}$ ).

All treatment contrasts significant at $\mathrm{p}<0.03$.

*Measured during 14-day run-in.

†Composite of scores for cough, wheeze, sputum production/colour and breathlessness, each measured twice daily on a four-point scale of increasing severity.

differed somewhat in study 2, particularly in the smoking subgroups, where ex-smokers had a mean difference of $50 \mathrm{ml}$ (advantage) over current smokers. Reasons for the difference are unknown but it could be due to the small sample size. Disease severity, smoking status and history were similar in the two studies, and the higher proportion of patients of Asian origin in study $2(16.5 \%$ vs $5 \%$ in study 1 , including $13.5 \%$ from India) did not influence treatment responsiveness (results not shown). The primary outcome was chosen to reflect the period of the day when patients are more active and when multiple spirometric assessments are more conveniently made. The results show an average increase in $\mathrm{FEV}_{1}$ of $120-130 \mathrm{ml}$ over this period with indacaterol plus tiotropium treatment versus tiotropium alone. The treatment differences from the analysis models in the two studies are compatible, with only small differences (of $10 \mathrm{ml}$ ) between studies. The average differences between the two treatments in their effect on trough $\mathrm{FEV}_{1}$ may be regarded as substantial compared with the $90-110 \mathrm{ml}$ margin previously reported in a meta-analysis with tiotropium over placebo. ${ }^{4}$

While $\mathrm{FEV}_{1}$ is important for diagnosing airflow obstruction and monitoring COPD progression, changes in $\mathrm{FEV}_{1}$ are poorly correlated with changes in dyspnoea. ${ }^{22}{ }^{23}$ Although the mechanisms of dyspnoea in patients with COPD are complex and multifactorial, lung hyperinflation, both static and dynamic, is an important physiological consideration. ${ }^{24-26}$ The significant increases in resting IC with indacaterol plus tiotropium treatment compared with tiotropium alone are consistent with a greater reduction in lung hyperinflation. However, functional residual capacity was not measured in these studies to confirm this process. In previous studies, increases in IC with bronchodilator therapies were associated with improvements in clinical outcomes, including dyspnoea, exercise tolerance, health status and exacerbations. ${ }^{23} 27-29$ Similarly, in the present studies, the statistically significant reductions in symptom scores and asneeded salbutamol use demonstrate clinical improvement with indacaterol plus tiotropium treatment compared with tiotropium alone.

Adverse events and serious adverse events were reported by similar percentages of patients for the two study groups. Combining the two classes of bronchodilators did not reveal any safety concerns compared with tiotropium alone during the 12week study. An increased incidence of cough with indacaterol

Table 4 Adverse events overall and most commonly occurring ( $\geq 2 \%$ in any treatment group)

\begin{tabular}{|c|c|c|c|c|}
\hline & \multicolumn{2}{|l|}{ Study 1} & \multicolumn{2}{|l|}{ Study 2} \\
\hline & $\begin{array}{l}\text { Indacaterol + tiotropium } \\
(\mathrm{n}=570)\end{array}$ & $\begin{array}{l}\text { Tiotropium + placebo } \\
(\mathrm{n}=561)\end{array}$ & $\begin{array}{l}\text { Indacaterol + tiotropium } \\
(\mathrm{n}=572)\end{array}$ & $\begin{array}{l}\text { Tiotropium + placebo } \\
(n=570)\end{array}$ \\
\hline Any adverse event (\% of patients) & 45.4 & 41.2 & 43.0 & 40.2 \\
\hline Cough & 10.4 & 3.7 & 9.1 & 4.4 \\
\hline Nasopharyngitis & 4.2 & 3.6 & 2.3 & 2.1 \\
\hline Muscle spasms & 2.3 & 0 & 0.3 & 1.1 \\
\hline Upper respiratory tract infection & 1.8 & 2.0 & 1.4 & 1.9 \\
\hline Dry mouth & 1.6 & 1.6 & 2.1 & 0.5 \\
\hline
\end{tabular}

COPD, chronic obstructive pulmonary disease. 
Table 5 Number (\%) of patients with notable values for plasma potassium, blood glucose, pulse rate, blood pressure and QTc interval (Fridericia's)

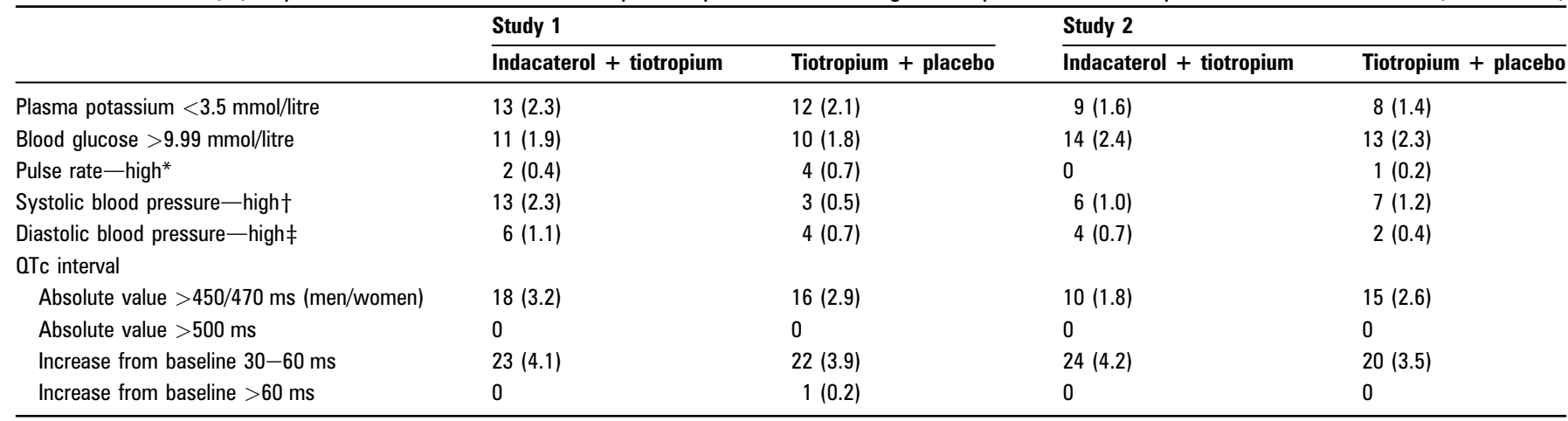

* $>130 \mathrm{bpm}$, or $\geq 120 \mathrm{bpm}$ and $\geq 15 \mathrm{bpm}$ increase from baseline.

$\dagger>200 \mathrm{~mm} \mathrm{Hg}$, or $\geq 180 \mathrm{~mm} \mathrm{Hg}$ and $\geq 20 \mathrm{~mm} \mathrm{Hg}$ increase from baseline.

$\ddagger>115 \mathrm{~mm} \mathrm{Hg}$, or $\geq 105 \mathrm{~mm} \mathrm{Hg}$ and $\geq 15 \mathrm{~mm} \mathrm{Hg}$ increase from baseline.

plus tiotropium treatment was observed in both studies. This side effect has been observed with indacaterol in previous studies, and was not associated with any loss of efficacy or increased

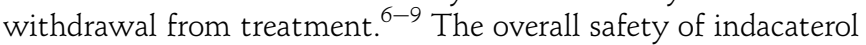
has been previously demonstrated in other clinical studies, including 1 year of treatment with a $600 \mu \mathrm{g}$ daily dose. ${ }^{6} 21$ Long-term clinical trials have shown that tiotropium has a good safety profile. ${ }^{5}$ 30-33

The enhanced efficacy of combining bronchodilator medications of different pharmacological classes has been recognised for many years, including the use of two short-acting agents ${ }^{12}{ }^{13}$ as well as the combination of tiotropium with twice-daily $\beta_{2}$ agonists. ${ }^{14-18}$ The putative mechanism for the additive effect of two different classes of once-daily bronchodilators as noted in our study could be the relaxation of bronchial smooth muscle secondary to independent effects on sympathetic and parasympathetic pathways. Alternative explanations may relate to differential distribution of $\beta_{2}$-adrenergic and muscarinic receptors within the airways, ${ }^{34}$ or to an interaction between the two types of receptors, with potentiation of $\beta_{2}$-receptor activation by muscarinic $\left(M_{3}\right)$ receptor blockade. ${ }^{16}$

There are several limitations of these two identical studies that demonstrate the efficacy and safety of indacaterol given concurrently with tiotropium. First, it would have been interesting to include indacaterol monotherapy as a third treatment arm. A direct comparison between indacaterol and tiotropium would provide important information for selecting initial longacting bronchodilator therapy for patients with COPD. ${ }^{10}$ However, a placebo tiotropium capsule for use with its proprietary dry powder inhaler is not available for administration in a double-blind study. A second limitation is that more comprehensive clinical measures were not included as secondary outcomes in these studies. The treatment effects on dyspnoea, health status and exacerbations are important clinical outcomes, and these measures should be included in subsequent clinical trials. ${ }^{35}$ Finally, the $150 \mu \mathrm{g}$ indacaterol dose was used in the current studies. This was the lower of two doses submitted for approval at the time that the studies were designed and initiated. The $150 \mu \mathrm{g}$ dose is currently approved in more than 50 countries, whereas 75 and $300 \mu \mathrm{g}$ doses have also received regulatory approval in different countries. Randomised trials will be required to assess the effects of these lower and higher doses of indacaterol in combination with tiotropium.

Current guidelines ${ }^{1-3}$ state that combining bronchodilators with different mechanisms of action increases the magnitude of bronchodilation for equivalent or less side effects. These are the first 12 -week studies to report on the efficacy of dual broncho- dilation using two once-daily bronchodilators. The improvements in lung function with the combination of indacaterol and tiotropium confirm GOLD recommendations. ${ }^{1}$ Concurrent administration of indacaterol and tiotropium is an effective treatment strategy for patients with moderate to severe COPD to promote bronchodilation and lung deflation with no additional safety signal.

Acknowledgements Sarah Filcek of CircleScience wrote the first draft of the manuscript and coordinated input from authors into subsequent drafts. This support was funded by Novartis. David Young of Novartis reviewed the manuscript. DATAMAP GmbH performed the statistical programming and analyses. David Lawrence of Novartis provided additional statistical support.

Contributors All authors had access to the study data, were involved in interpretation and/or presentation of the data for this report, reviewed and revised the initial draft and subsequent versions of the manuscript, had final responsibility for the decision to submit for publication and approved the version submitted.

Funding The study was funded by Novartis Pharma AG, the manufacturer of indacaterol. Novartis designed the study and analysed the data. Data were recorded at participating clinical centres and maintained by Novartis.

Competing interests DAM has received remuneration for participation in advisory boards and/or consulting from AstraZeneca, Boehringer-Ingelheim, DeepBreeze, Forest, GlaxoSmithKline, Merck, Nycomed, Novartis, and Sunovion. AD has received research, consulting and lecturing fees from GlaxoSmithKline, Sepracor, Schering Plough, Altana, Methapharma, AstraZeneca, ONO pharma, Novartis Canada/USA, Hoffmann-La Roche Limited, and KOS Pharmaceuticals. EDB has received remuneration for lectures, participation in advisory boards and/or consulting from Amgen, Almirall, Alk Abello, Actelion, AstraZeneca, Boehringer Ingelheim, Elevation Pharma, Forest, GlaxoSmithKline, Merck, Nycomed, Novartis and Pfizer. SAÖ has received research grants from Novartis and Boehringer-Ingelheim. TW, CP, CL and BK are employees of Novartis, the study sponsor.

Patient consent Patients gave their written informed consent to participate before receiving any study treatment. Patients are not identifiable by the information given in the manuscript.

Ethics approval The study design was approved by independent ethics committees or review boards at each centre. Patients gave their written informed consent to participate before receiving any study treatment.

Provenance and peer review Not commissioned; externally peer reviewed.

\section{REFERENCES}

1. Global Initiative for Chronic Obstructive Lung Disease (GOLD). Global Strategy for the Diagnosis, Management, and Prevention of Chronic Obstructive Pulmonary Disease. 2010. http://www.goldcopd.com (accessed 1 Feb 2011).

2. Celli BR, MacNee W; ATS/ERS Task Force. Standards for the diagnosis and treatment of patients with COPD: a summary of the ATS/ERS position paper. Eur Respir J 2004;23:932-46. Erratum in: Eur Respir J 2006;27:242.

3. O'Donnell DE, Aaron S, Bourbeau J, et al; Canadian Thoracic Society. State of the Art Compendium: Canadian Thoracic Society recommendations for the management of chronic obstructive pulmonary disease. Can Respir J 2004;11(Suppl B):7B-59.

4. Barr RG, Bourbeau J, Camargo CA, et al. Tiotropium for stable chronic obstructive pulmonary disease: a meta-analysis. Thorax 2006;61:854-62. Erratum in: Thorax 2007;62:191. 
5. Tashkin DP, Celli B, Senn S, et al. A 4-year trial of tiotropium in chronic obstructive pulmonary disease. N Engl J Med 2008;359:1543-54.

6. Dahl R, Chung KF, Buhl R, et al; INVOLVE (Indacaterol: Value in COPD: Longer Term Validation of Efficacy and Safety) Study Investigators. Efficacy of a new once-daily long-acting inhaled $\beta_{2}$-agonist indacaterol versus twice-daily formoterol in COPD. Thorax 2010;65:473-9.

7. Kornmann 0, Dahl R, Centanni S, et al; INLIGHT-2 (Indacaterol Efficacy Evaluation Using 150- $\mu$ g Doses with COPD Patients) Study Investigators. Once-daily indacaterol vs twice-daily salmeterol for COPD: a placebo-controlled comparison. Eur Respir J 2011; $37: 273-9$

8. Korn S, Kerwin E, Atis $\mathrm{S}$, et al. Indacaterol once-daily provides superior efficacy to salmeterol twice-daily in COPD: a 12-week study. Respir Med 2011:105:719-26.

9. Donohue JF, Fogarty C, Lötvall J, et al; INHANCE Study Investigators. Once-daily bronchodilators for chronic obstructive pulmonary disease: indacaterol versus tiotropium. Am J Respir Crit Care Med 2010:182:155-62.

10. Buhl R, Dunn LJ, Disdier C, et al. Blinded 12-week comparison of once-daily indacaterol and tiotropium in COPD. Eur Respir J 2011:38:797-803.

11. Vogelmeier C, Ramos-Barbon D, Jack D, et al; INTIME Study Investigators (Indacaterol \& Tlotropium: Measuring Efficacy). Indacaterol provides 24-hour bronchodilation in COPD: a placebo-controlled blinded comparison with tiotropium. Respir Res 2010;11:135.

12. Anon. In chronic obstructive pulmonary disease, a combination of ipratropium and albuterol is more effective than either agent alone. An 85-day multicenter trial. COMBIVENT Inhalation Aerosol Study Group. Chest 1994;105:1411-19.

13. Anon. Routine nebulized ipratropium and albuterol together are better than either alone in COPD. COMBIVENT Inhalation Solution Study Group. Chest 1997; 112:1514-21.

14. van Noord JA, Aumann JL, Janssens E, et al. Comparison of tiotropium once daily, formoterol twice daily and both combined once daily in patients with COPD. Eur Respir J 2005;26:214-22.

15. van Noord JA, Aumann JL, Janssens E et al. Effects of tiotropium with and without formoterol on airflow obstruction and resting hyperinflation in patients with COPD. Chest 2006;129:509-17.

16. van Noord JA, Aumann $\mathrm{JL}$, Janssens $\mathrm{E}$, et al. Combining tiotropium and salmeterol in COPD: effects on airflow obstruction and symptoms. Respir Med 2010;104:995-1004.

17. Vogelmeier C, Kardos P, Harari S, et al. Formoterol mono- and combination therapy with tiotropium in patients with COPD: a 6-month study. Respir Med 2008:102:1511-20.

18. Tashkin DP, Pearle J, lezzoni D, et al. Formoterol and tiotropium compared with tiotropium alone for treatment of COPD. COPD 2009;6:17-25.

19. van Noord JA, Buhl R, LaForce C, et al. OVA149 demonstrates superior bronchodilation compared with indacaterol or placebo in patients with chronic obstructive pulmonary disease. Thorax 2010;65:1086-91.
20. Global Initiative for Chronic Obstructive Lung Disease (GOLD). Global Strategy for the Diagnosis, Management, and Prevention of Chronic Obstructive Pulmonary Disease. 2007. http://www.goldcopd.com (accessed 1 Feb 2011).

21. Chapman KR, Rennard SI, Dogra A, et al. Long-term safety and efficacy of indacaterol, a novel long-acting $\beta_{2}$-agonist, in subjects with COPD: a randomized, placebo-controlled study. Chest 2011:140:68-75.

22. Mahler DA, Weinberg DH, Wells CK, et al. The measurement of dyspnea. Contents interobserver agreement, and physiologic correlates of two new clinical indexes. Chest 1984:85:751-8.

23. Celli B, ZuWallack R, Wang $S$, et al. Improvement in resting inspiratory capacity and hyperinflation with tiotropium in COPD patients with increased static lung volumes. Chest 2003:124:1743-8.

24. O'Donnell DE, Lam M, Webb KA. Measurement of symptoms, lung hyperinflation, and endurance during exercise in chronic obstructive pulmonary disease. Am J Respir Crit Care Med 1998:158:1557-65.

25. Diaz 0, Villafranca $\mathrm{C}$, Ghezzo $\mathrm{H}$, et al. Role of inspiratory capacity on exercise tolerance in COPD patients with and without tidal expiratory flow limitation at rest. Eur Respir J 2000;16:269-75.

26. Taube C, Lehnigk B, Paasch K, et al. Factor analysis of changes in dyspnea and lung function parameters after bronchodilation in chronic obstructive pulmonary disease. Am J Respir Crit Care Med 2000;162:216-20.

27. O'Donnell DE, Lam M, Webb KA. Spirometric correlates of improvement in exercise performance after anticholinergic therapy in chronic obstructive pulmonary disease. Am J Respir Crit Care Med 1999;160:542-9.

28. Verkindre C, Bart F, Aguilaniu B, et al. The effect of tiotropium on hyperinflation and exercise capacity in chronic obstructive pulmonary disease. Respiration 2006; 73:420-7.

29. Tantucci C, Donati P. Nicosia F, et al. Inspiratory capacity predicts mortality in patients with chronic obstructive pulmonary disease. Respir Med 2008;102:613-19.

30. Michele TM, Pinheiro S, lyasu S. The safety of tiotropium-the FDA's conclusions. N Engl J Med 2010:363:1097-9.

31. Kesten S, Celli B, Decramer M, et al. Tiotropium HandiHaler in the treatment of COPD: a safety review. Int J Chron Obstruct Pulmon Dis 2009;4:397-409.

32. Celli B, Decramer M, Leimer I, et al. Cardiovascular safety of tiotropium in patients with COPD. Chest 2010;137:20-30.

33. Rodrigo GJ, Castro-Rodriguez JA, Nannini LJ, et al. Tiotropium and risk for fatal and nonfatal cardiovascular events in patients with chronic obstructive pulmonary disease: systematic review with meta-analysis. Respir Med 2009;103:1421-9.

34. Barnes PJ. Distribution of receptor targets in the lung. Proc Am Thorac Soc 2004;1:345-51.

35. Cazzola M, MacNee W, Martinez FJ, et al; American Thoracic Society; European Respiratory Society Task Force on outcomes of COPD. Outcomes for COPD pharmacological trials: from lung function to biomarkers. Eur Respir $J$ 2008:31:416-69. 